\title{
Impact of approach used to determine removal levels of drugs of abuse during wastewater treatment
}

\author{
Angela Rodayan ${ }^{\mathrm{a}}$, Marius Majewsky ${ }^{\mathrm{b}}$, Viviane Yargeau ${ }^{\mathrm{a}, *}$ \\ a Department of Chemical Engineering, McGill University, 3610 University St., Montreal, QC J3N 1V3, Canada \\ ${ }^{\mathrm{b}}$ Karlsruhe Institute of Technology (KIT), Engler-Bunte-Institut, Chair of Water Chemistry and Water Technology, Engler-Bunte-Ring 1, 76131 Karlsruhe, Germany
}

\section{H I G H L I G H T S}

- 19 drugs of abuse were studied throughout a wastewater treatment plant.

- Drug levels were generally comparable between composite, POCIS and grab samples.

- Overall drug removals during wastewater treatment varied between -84 and $90 \%$.

- Time-shifted mass balancing eliminated negative removals obtained with other approaches.

\section{A R T I C L E I N F O}

\section{Article history:}

Received 2 February 2014

Received in revised form 3 March 2014

Accepted 7 March 2014

Available online 13 April 2014

Editor: D. Barcelo

\section{Keywords:}

Cocaine

Amphetamine-type stimulants

Opioids

Passive sampling

Removal efficiency

Time shifted mass balancing

\begin{abstract}
A B S T R A C T
In this study the levels of 19 drugs of abuse were estimated throughout a wastewater treatment plant using polar organic chemical integrative samplers (POCIS), $24 \mathrm{~h}$ composite samples and grab samples. Overall removal efficiencies and removals in between each treatment unit were calculated using load data for each sampling technique as well as removals that take into account the hydraulic residence time distribution of the treatment plant (time-shifted mass balancing approach). Amphetamine-type stimulants, cocaine and its major metabolite, benzoylecgonine and opioid levels determined with $24 \mathrm{~h}$ composite samples were generally comparable to those obtained with POCIS and grab samples. Negative mass balances resulting from the estimation of overall removal efficiencies by POCIS, day-to-day mass balancing of $24 \mathrm{~h}$ composite and grab sample data did not occur when the hydraulic retention time (HRT) distributions of the plant were taken into account for calculation. Among the compounds investigated, cocaine exhibited the highest overall removal (90\%) while codeine had the lowest with $13 \%$, respectively. Sampling between the treatment units revealed that highest removal occurs during biological treatment as compared to primary or secondary clarification. Methylenedioxyamphetamine (MDA), fentanyl, dihydrocodeine and heroin were not detected in wastewater at any of the sampling locations at the treatment plant regardless of the sampling technique. The study demonstrates the benefits of applying the time-shifted mass balancing approach to the calculation of removals of drugs of abuse during wastewater treatment.
\end{abstract}

(c) 2014 Elsevier B.V. All rights reserved.

\section{Introduction}

Illicit drugs are used worldwide and in fact the United Nations Office on Drugs and Crime (UNODC) reported that between 149 and 272 million people used illicit drugs at least once in 2008 (UNODC, 2008). Under the category of drugs of abuse (DOAs) are both illicit drugs and prescribed drugs that are abused. Human consumption and excretion of these compounds lead to their (or their metabolites') presence in wastewater and have therefore been detected in wastewater and surface waters in several countries (Boleda et al., 2007; Bones et al., 2007; Castiglioni et al., 2006; Gheorghe et al., 2008; Huerta-Fontela et al., 2007; Hummel et al., 2006; Irvine et al., 2011; Kasprzyk-Hordern

\footnotetext{
* Corresponding author. Tel.: +1 514398 2273; fax: +1 5143986678

E-mail address: viviane.yargeau@mcgill.ca (V. Yargeau).
}

et al., 2009; Metcalfe et al., 2010; Nefau et al., 2013; Pedrouzo et al., 2011; Postigo et al., 2011; Zuccato and Castiglioni, 2009).

While environmental fate assessment for a variety of pharmaceuticals and personal care products has been accomplished and rests upon a broad data base of studies investigating their fate during the last decade, the current picture of DOAs is still ambiguous in this regard. With wastewater treatment plants being the major pathway to surface waters and given the significant uncertainties about their amounts of consumption, the need for reliable data about their levels and removals in wastewater treatment plants (WWTPs) is apparent.

Reported WWTP removal efficiencies vary to a large extent and also negative removal efficiencies have been observed in some studies. In the latter case, the level of the investigated compound is higher in the effluent than that in the influent to one of the treatment units or over the entire WWTP (Blair et al., 2013). Reasons for this can include the 
release of fecal particles during wastewater treatment, significant desorption from the return activated sludge thereby increasing their concentration throughout the treatment process (Göbel et al., 2007; Salgado et al., 2012) or the transformation of conjugate compounds to the parent compound during biological treatment (Monteiro and Boxall, 2010; Salgado et al., 2012). Negative removals for compounds that are not excreted from the human body, such as pesticides, pharmaceuticals and personal care products have also been reported, making the latter reason less likely. The principal source of error is most likely the applied sampling strategy. Although it has been recognized that loads can vary greatly from day to day or over time during a day and that sampling can be a dominant source of uncertainty in many applications (Ramsey and Thompson, 2007), usually little attention is given to the set-up of adequate sampling strategies. Consequently, since advanced analytical methodologies for the detection of emerging micropollutants are now available, unsuitable sampling increasingly represents a major source of inaccuracy (Ort et al., 2010b).

Ort et al. (2010a) assessed how sampling strategies were addressed in numerous studies and found that only few provided justification for the choice of sampling technique, duration, mode and frequency. Most studies that have monitored the levels of DOAs in wastewater used grab samples or isolated 24-h composite samples of the influent and effluent of the WWTP (Bones et al., 2007; Mazzella et al., 2007; Postigo et al., 2008b) and did not consider the HRT or mixing in the treatment tanks for the estimation of full-scale removal efficiencies.

Grab sampling does not capture short or long-term concentration variation since it takes an instantaneous picture of the concentration of the contaminants in the water at the time of sampling. In addition, in most cases the sampling frequency for composite sampling is longer than $1 \mathrm{~h}$ and since pollutant peaks generally extend over only a few minutes, the error can be quite large. It is therefore recommended to keep the sampling interval as short as possible given the constraints of the automated sampler. In fact, time proportional as opposed to flow proportional sampling can over- or underestimate the contaminant concentration but it is acknowledged that it is not always feasible to carry out a flow proportional sampling campaign (Ort et al., 2010b). In addition, over a short time period the discharge flow from a WWTP is generally quite stable and therefore flow proportional sampling may not significantly reduce sampling error.

Basing the estimation of full-scale removal estimations on influenteffluent load mass balances requires considering the hydraulic retention time and mixing of the water parcel in the tanks. As treatment tanks can usually be regarded as well-mixed systems, an influent-effluent mass balance of daily loads does not provide an adequate capture of the influent load and is therefore not valid. As a consequence, erroneous removal efficiencies are obtained from the comparison of two largely different water volumes (Majewsky et al., 2011).

To design the sampling campaign for the WWTP for the present study, prior hydraulic calibration is necessary using an artificial tracer or a routinely taken measurement such as the water's electrical conductivity (EC) (Anhert et al., 2010; Olivet et al., 2005). Once calibrated, the model can be used to determine an optimal sampling strategy as well as the influent fraction captured by effluent sampling, which takes into account the hydraulic mixing regimes of the WWTP under study to yield reliable mass balances. To our knowledge, no studies have implemented time-shifted mass balancing for the measurement of DOAs in wastewater to date.

Moreover, among sampling techniques applied for micropollutant sampling, passive sampling recently has gained popularity providing a cost effective way to monitor time-weighted average concentrations of organic chemicals in aquatic systems (Greenwood et al., 2007). Polar organic chemical integrative samplers (POCIS) developed by Alvarez et al. (2004) have been shown to be suitable for measuring compounds such as pharmaceuticals, in wastewater (Mazzella et al., 2007; Mills et al., 2007; Petty et al., 2004; Zhang et al., 2008) but few studies have used POCIS for monitoring DOAs (Harman et al., 2011;
Jones-Lepp et al., 2012; Yargeau et al., in press). An advantage of using POCIS is that since the samplers are deployed over extended periods of time, the quantification of residues from random events and the identification of contaminants that are at ultra-low levels can be carried out, both of which are generally missed when grab sampling is employed. A current drawback of these samplers is that to measure the amount of chemical adsorbed, the sampler must first be calibrated for the target compounds by determining their sampling rates $\left(\mathrm{R}_{\mathrm{s}}\right.$ in $\left.\mathrm{Ld}^{-1}\right)$. Since the technology is still developing, many uptake rates have yet to be determined and $R_{S}$ obtained in the laboratory can be quite different from those in the field (Bailly et al., 2013). In addition, fouling and clogging of POCIS, especially in untreated wastewater can limit its deployment time.

The behavior of DOAs during wastewater treatment is only partially understood and must therefore be further considered in order to control their release into the environment and avoid any potential adverse effects on aquatic ecosystems. A better understanding of the occurrence and removal of DOAs to control their release into the environment and avoid any potential adverse effects on aquatic ecosystems can only be achieved on the basis of reliable empirical data being inherently connected to well-defined sampling strategies.

As a consequence, the goals of this study were to determine the levels of the selected DOAs in the influent and effluent as well as in between each treatment unit at a WWTP in Quebec, Canada using POCIS and $24 \mathrm{~h}$ composite (for four consecutive days) sampling. In addition, grab samples were taken at each sampling point as a way to confirm the inadequacy of this sampling mode in obtaining reliable results. Removal efficiencies of each DOA throughout the treatment process were calculated by conventional input-output mass balancing for POCIS and $24 \mathrm{~h}$ composites. Additionally, correction for HRT and mixing over the whole plant as well as between the units was considered to confirm or reject the applicability and reliability of the three sampling approaches.

\section{Methods}

\subsection{Chemicals, reagents and supplies}

The DOAs used in this study were from several classes of drugs and are listed in Table 1. Analytical standards of all target compounds and their deuterated analogs were obtained from Cerilliant (Round Rock, TX, USA) at a purity higher than $99 \%$. The deuterated stable isotope surrogates were used to correct for extraction recoveries and matrix effects. Working solutions and calibration standards prepared by appropriate dilution of stock solutions were stored in amber glass bottles at $-20{ }^{\circ} \mathrm{C}$ and were used directly from the freezer since they were in pure solvent or in a mixture of solvent and water.

Optima liquid chromatography-mass spectrometry (LC-MS) grade methanol, acetonitrile, and water were used for LC-MS analysis and were purchased from Fisher Scientific (Ottawa, ON, Canada). High performance liquid chromatography (HPLC grade or equivalent) acetone, acetonitrile, methanol, ACS reagent grade dichloromethane (DCM), hydrochloride acid (37\%), sulphuric acid (96\%), formic acid (88\%), trace metal grade ammonium hydroxide (88\%) and sodium sulfate were purchased from Fisher Scientific (Ottawa, ON, Canada). Ultrapure water was obtained using a Milli-Q water purification system from Millipore (Bedford, MA, USA). Pharmaceutical POCIS containing 200 mg Waters Oasis (R) Hydrophilic-Lipophilic Balance sorbent were purchased from Environmental Sampling Technologies (EST Labs, St. Joseph, MO, USA). The sorbent was held between two polyethersulfone membranes which were compressed between two stainless steel washers. Whatman $1.5 \mu \mathrm{m}$ glass microfiber filters were purchased from Fisher Scientific (Ottawa, ON, Canada) and Oasis MCX cation exchange cartridges $(6 \mathrm{~mL} / 150 \mathrm{mg})$ were purchased from Waters Corporation (Milford, MA, USA). 
Table 1

List of target compounds, corresponding deuterated analogs, molecular weights, LODs and LOQs, SPE recoveries, POCIS extraction efficiencies and POCIS sampling rates.

\begin{tabular}{|c|c|c|c|c|c|}
\hline Target compound (surrogates) & Target compound MW & LOD, LOQ $\left(\mathrm{ng} \mathrm{L}^{-1}\right)$ & SPE recovery (\%) & POCIS extraction efficiency (\%) & POCIS sampling rate ${ }^{a}\left(R_{s} \pm S D\right)$ \\
\hline \multicolumn{6}{|l|}{ Cocaine and its metabolite } \\
\hline Cocaine (cocaine-d3) & 303.4 & $1.3,4.2$ & 90 & 89 & $0.230 \pm 0.036$ \\
\hline Benzoylecgonine (benzoylecgonine-d3) & 289.3 & $1.3,4.2$ & 96 & 85 & $0.134 \pm 0.011$ \\
\hline \multicolumn{6}{|l|}{ Amphetamine-type stimulants } \\
\hline Amphetamine (amphetamine-d5) & 135.2 & $1.1,3.5$ & 98 & 93 & $0.201 \pm 0.038$ \\
\hline Methamphetamine (methamphetamine-d9) & 149.2 & $2.1,6.9$ & 99 & 92 & $0.231 \pm 0.025$ \\
\hline MDA (MDA-d5) & 179.2 & $1.0,3.2$ & 95 & 91 & $0.288 \pm 0.021$ \\
\hline MDMA (MDMA-d5) & 193.2 & $2.5,8.4$ & 95 & 90 & $0.222 \pm 0.013$ \\
\hline Ephedrine (ephedrine-d3) & 165.2 & $1.7,5.6$ & 88 & 82 & $0.123 \pm 0.039$ \\
\hline \multicolumn{6}{|l|}{ Opioid drugs } \\
\hline Codeine (codeine-d3) & 299.4 & $0.91,3.0$ & 87 & 83 & $0.394 \pm 0.049$ \\
\hline Acetylcodeine (acetylcodeine-d9) & 341.4 & $1.5,4.9$ & 86 & 85 & $N A^{b}$ \\
\hline Dihydrocodeine (dihydrocodeine-d6) & 301.4 & $0.42,1.4$ & 86 & 82 & $0.110 \pm 0.041$ \\
\hline Morphine (morphine-d3) & 285.3 & $0.27,0.89$ & 90 & 88 & $0.261 \pm 0.036$ \\
\hline Acetylmorphine (acetylmorphine-d3) & 327.4 & $0.14,0.48$ & 85 & 81 & $N A^{b}$ \\
\hline Methadone (methadone-d9) & 309.4 & 21,69 & 90 & 85 & $0.408 \pm 0.147$ \\
\hline Heroin (heroin-d9) & 369.4 & $1.8,6.1$ & 87 & 83 & $N A^{b}$ \\
\hline Tramadol (tramadol-d6) & 263.4 & $1.8,5.8$ & 83 & 81 & $0.241 \pm 0.062$ \\
\hline Ketamine (ketamine-d4) & 237.7 & $0.51,1.7$ & 82 & 83 & $0.590 \pm 0.021$ \\
\hline Oxycodone (oxycodone-d3) & 315.4 & $1.4,4.8$ & 88 & 84 & $0.152 \pm 0.039$ \\
\hline EDDP (EDDP-d3) & 277.1 & 22,74 & 86 & 83 & $0.532 \pm 0.193$ \\
\hline Fentanyl (fentanyl-d5) & 336.5 & $1.1,3.6$ & 81 & 81 & $1.17 \pm 0.160$ \\
\hline
\end{tabular}

a Taken from Yargeau et al. (in press) with the exception of the $\mathrm{R}_{\mathrm{s}}$ of ketamine and fentanyl.

b Sampling rate not available.

\subsection{Sample collection and WWTP data}

All samples were obtained from the WWTP in Gatineau, QC, Canada. The WWTP employs activated sludge treatment (See Fig. 1 for plant schematic). Sampling was conducted for all three approaches at the exit of the grit removal chamber (Untreated WW), primary clarifiers (Influent to Aeration) and aeration basins (Influent to secondary clarifier) and in the effluent (Treated WW), as denoted in Fig. 1.

The average flow received by the plant is $127,400 \mathrm{~m}^{3} \mathrm{~d}^{-1}$ (2011) and it serves a population of approximately 235,000 habitants. The concentration of suspended solids in the treated water was measured to be $6.4 \mathrm{mg} \mathrm{L}^{-1}$ using Standard Method \#2540D. The chemical oxygen demand was measured to be $36 \mathrm{mg}$ L using a HACH Digital Reactor Block 200 (DRB 200) and a HACH spectrophotometer DR/2500. Average data for biochemical oxygen demand $\left(\mathrm{BOD}_{5}\right)$ and total phosphorus were obtained by plant personnel and were 3.9 and $0.41 \mathrm{mg} \mathrm{L}^{-1}$, respectively.

\subsubsection{Grab and composite sample collection}

Grab samples were collected in $1 \mathrm{~L}$ pre-cleaned amber bottles on August 13 and 27, 2012. Composite samples were taken over a four

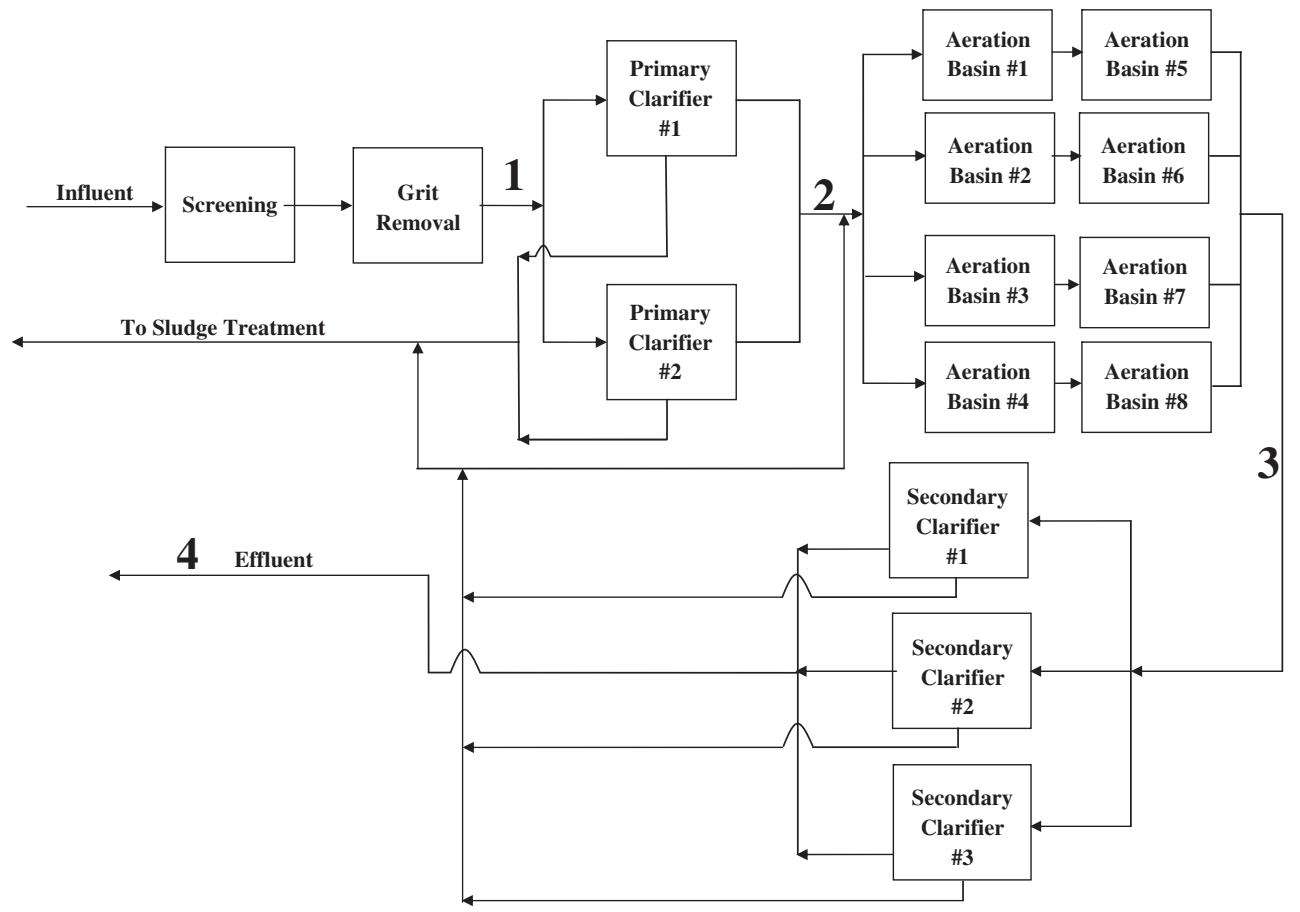

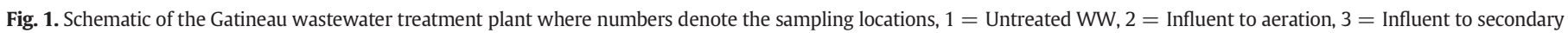
clarifier and $4=$ Treated WW. 
day period of August 13 to 17, 2012 using Isco 6712 samplers equipped with a 24 plastic bottle collection system packed with ice (Avensys, St-Laurent, QC, Canada). Samples were taken in $50 \mathrm{~mL}$ volumes every 45 min over the four day period. Flow data at a 10 minute time-scale were provided by plant operators but the average flow into the treatment plant over the composite sampling period was $5718 \pm$ $948 \mathrm{~m}^{3} \mathrm{~h}^{-1}$ and the mean HRT for the overall treatment plant during dry weather was $12 \mathrm{~h}$.

\subsubsection{POCIS deployment}

POCIS were deployed on August 13, 2012 for 14 days at each of the sampling locations identified in Fig. 1 and debris accumulating on the samplers were removed daily. POCIS disks were kept in tight canisters prior to deployment and three disks were transferred to stainless steel cages upon arrival at each location at the WWTP and deployed shortly after. POCIS field blanks were exposed to ambient air during the deployment and retrieval of the POCIS samplers. Once removed from the cages each POCIS disk was wrapped in aluminum foil and stored in a sealable plastic bag. All aqueous samples and POCIS were stored in a cooler at $4{ }^{\circ} \mathrm{C}$ during transportation to the laboratory where they were then stored at $-20{ }^{\circ} \mathrm{C}$ until extraction, which was carried out within three weeks of retrieval. The average flow rate to the WWTP over the deployment period was $5796 \mathrm{~m}^{3} \mathrm{~h}^{-1}$.

\subsubsection{Electrical conductivity (EC) measurement}

Electrical wastewater conductivity and temperature were measured at intervals of $30 \mathrm{~s}$ with HOBO conductivity loggers (Hoskin Scientific, St-Laurent, QC, Canada) at the four sampling locations over a four week period in April, 2012 for hydraulic model calibration and during the composite sampling campaign between August 13 and 17, 2012 for further validation of the calibration. A universal optic-USB base station and Onset HOBOware Pro Version 3.2.2 software (Hoskin Scientific, St-Laurent, QC, Canada) were used for data transfer and read out, respectively.

\subsection{Plant layout, calibration \& residence time distribution}

Model calibration and determination of HRT distributions were based on the method proposed by Majewsky et al. (2011). Briefly, the Gatineau WWTP plant layout was modeled using the wastewater modeling software GPS-X from Hydromantis (Hamilton, Canada). Volumes, tank operation and sequencing were chosen according to the data supplied by the WWTP staff. For hydraulic calibration, untreated wastewater EC was fed to the model and iteratively fit to the measured effluent data to determine the best model in terms of the number of completely mixed tanks-in-series and the number and type of secondary clarifiers. The EC varied sufficiently over both data collection periods to enable the use of the data for the hydraulic calibration of the WWTP. Of course, if large enough fluctuations of EC were not observed over the deployment period, the data could not be used to accurately calibrate the WWTP. Considering that the data of the untreated wastewater were strongly biased due to high ionic strength, clogging or biofouling, the EC data from the influent to aeration sampling point was fed to the model as input. This approach did not result in significant difference in the modeling, suggesting that the mixing in the primary clarifier does not significantly impact the accuracy of the overall modeling results. Both Chi square and Pearson's correlation coefficient were used as criteria to decide which model was best suited to describe the mixing behavior of the plant. The calibrated model was then used to determine the residence time distribution of an analyte within the plant by running a simulation based on a single influent pulse with a duration of $24 \mathrm{~h}$.

\subsection{Aqueous sample extraction}

Grab and composite samples were vacuum filtered using $1.5 \mu \mathrm{m}$ glass fiber filters, adjusted to a $\mathrm{pH}$ of 2.5 using sulphuric acid and spiked with $100 \mu \mathrm{L}$ of $500 \mathrm{ng} \mathrm{mL}^{-1}$ surrogate standard mixture prior to preconcentration using solid phase extraction (SPE). Automated SPE was carried out using a Gilson GX-271 ASPECTM instrument with $6 \mathrm{~mL}-150 \mathrm{~g}$ Oasis MCX cartridges (Waters, Milford, USA). The extraction method was based on a previously published method for illicit drugs (Metcalfe et al., 2010) that was modified to include opioid drugs (Yargeau et al., in press). Briefly, the cartridges were pre-conditioned with $6 \mathrm{~mL}$ of acetone, $6 \mathrm{~mL}$ methanol and $6 \mathrm{~mL}$ milli-Q water adjusted to $\mathrm{pH}$ 2.5. The samples ( $200 \mathrm{~mL}$ for WWTP effluent and $100 \mathrm{~mL}$ for all other sampling points) were loaded onto the cartridges at a rate of $5 \mathrm{~mL} \mathrm{~min}{ }^{-1}$, aspired to dryness and eluted with $8 \mathrm{~mL}$ of $5 \%$ ammonium hydroxide in methanol. The eluent was evaporated to almost dryness using a Savant SPD 131DDA Speed Vac Concentrator connected to a RVT4104 refrigerated vapor trap (Thermo Fisher Scientific, Waltham, MA). The samples were reconstituted to a volume of $0.4 \mathrm{~mL}$ in $25 \%$ water/75\% methanol and a $25 \mu \mathrm{L}$ aliquot of the sample extract was injected directly into the LC-MS system for analysis. All samples were extracted in triplicate. Procedural blanks were also pre-concentrated to measure the SPE recoveries of the target compounds and their deuterated analogs. All recoveries were $>80 \%$ and are listed in Table 1 .

\subsection{POCIS extraction and sampling rates}

POCIS samplers were extracted according to methods previously described by Li et al. (2010).

Briefly, the POCIS were extracted by placing the sorbent into the glass column, washing it with methanol and spiking it with a mixture of the deuterated analogs of the compounds of interest, followed by elution with methanol, drying and preparation for analysis. Extraction efficiencies ( $>80 \%$ for all compounds) and the sampling rates $\left(R_{s}\right)$ used in the calculations are listed in Table 1. POCIS data were not obtained for acetylcodeine, acetylmorphine and heroin because of the missing $R_{S}$ values for these compounds.

\subsection{Analysis}

Liquid chromatography-high resolution mass spectrometry (LC-HRMS) using an Accela LC system coupled to a LTQ Orbitrap XL (Thermo Fisher Scientific, Waltham, MA) was used to measure analyte concentrations. Chromatographic separation of the target compounds was achieved using the method described in Rodayan et al. (in press). Ionization was done in positive mode using a heated electrospray ionization (HESI) source with the following parameters: sheath gas flow $=45$ arbitrary units, auxiliary sheath gas flow $=10$ arbitrary units, capillary temperature $=375{ }^{\circ} \mathrm{C}$, capillary voltage $=5 \mathrm{~V}$, and tube lens $=100 \mathrm{~V}$. Acquisition was performed in full scan mode $(50-400 \mathrm{~m} / \mathrm{z})$ at high resolution $\left(R_{\mathrm{FWHM}}=41,000\right)$ and analyte quantification was carried out by extracting the ion of interest using an $m / z$ window of \pm 0.01 and confirmation by MS/MS spectra using a data dependent MS/MS experiment. An eight-point calibration curve generated for each compound in the range of 3-150 $\mu \mathrm{g} \mathrm{L} \mathrm{L}^{-1}$ was used for quantification with a constant deuterated stable isotope surrogate concentration of $100 \mu \mathrm{g} \mathrm{L}^{-1}$. The linear correlation coefficients were at least 0.993 for all analytes studied.

The limits of detection (LODs) and limits of quantification (LOQs) for the analytes in wastewater were in the range of 0.14 to $22 \mathrm{ng} \mathrm{L}^{-1}$ and 0.48 to $74 \mathrm{ng} \mathrm{L}^{-1}$, respectively (see Table 1 ). These were determined by a signal to noise ratio of $>3$ for the LODs and $>10$ for the LOQs and method validation was done using spiked samples of wastewater. The analytical methodology was validated in terms of repeatability between runs on the same day and measured as the relative standard deviation (RSD) of three injections in wastewater and was found to be $\leq 13 \%$. In addition, reproducibility between days was measured as the RSD $(\%, \mathrm{n}=3)$ and was $\leq 17 \%$. Quality controls were included in every sample series to control the performance of the analytical instrumentation. The relative error between the measured concentration and the 
expected concentration was always $<10 \%$ for all target compounds. Field blank POCIS were processed the same way as described for the sample POCIS and no analyte residues were detected.

\section{Results and discussion}

\subsection{Model calibration, residence time distribution E' sampling scenario}

Minimizing the Chi square between modeled and measured treated wastewater EC values resulted in a model consisting of 4 lanes with $\mathrm{n}=4$ completely mixed tanks-in-series and 3 sloping bottom secondary clarifiers to best describe the mixing behavior at the Gatineau WWTP.

Once the model was calibrated, the transition time and hydraulic mixing behavior of a $24 \mathrm{~h}$ influent load through the plant were simulated by use of a pulse injection and dry weather diurnal flow data. The simulated effluent loads (Treated WW) allowed the estimation of the fraction of an influent load (Untreated WW) that is captured by a given effluent sampling duration. The detailed description of method and an experimental case study can be found elsewhere (Majewsky et al., 2011, 2013). For the Gatineau plant, it was found that a sampling duration of $24 \mathrm{~h}$ captures $52 \%$ of the influent load that entered the WWTP the same day when starting the autosamplers simultaneously. This demonstrates that a daily water volume is distributed over more than one day when discharged in the effluent. Based on this, the sampling strategy can be designed to account for the transition time and mixing and to allow for adequate calculation of the mass balances using these fractions. As a result, a sampled $24 \mathrm{~h}$ effluent load was composed of $2 \%$ of the load that entered the plant two days ago, $46 \%$ of the load that entered one day ago and $52 \%$ of the load that entered the same day. It was therefore determined that sampling one more day in the influent than in the effluent with a time lag of $24 \mathrm{~h}$ between the start of the influent and effluent sampling was the optimal sampling strategy.

To calculate the removals for the single treatment units, the captured fractions were analogously calculated for the biological treatment unit, which resulted in $23 \%$ (of the load that entered the plant one day ago) and $77 \%$ (same day). The removal of each analyte across the secondary clarifiers was then calculated by subtracting the removal until the secondary clarifier (after biological treatment) from the overall removal.

\subsection{Levels of DOAs in wastewater}

Table 2 summarizes the data for the selected compounds. Table 2 presents the mean concentrations ( $\mathrm{ng} \mathrm{L}^{-1}, \pm$ one standard deviation) of each analyte at the four sampling points at the Gatineau WWTP for POCIS $(n=3$ ), traditional $24 \mathrm{~h}$ composite samples (average of triplicate samples taken on four consecutive days) and grab samples ( $n=6$, triplicate samples taken on the same days that the POCIS were deployed and picked up). For all sampling techniques, MDA, heroin, fentanyl and dihydrocodeine were below their respective LODs or LOQs. In addition, heroin, acetylcodeine and acetylmorphine were omitted for POCIS data since their $R_{\mathrm{s}}$ are not available.

In untreated wastewater, the highest levels were observed for BE followed by cocaine and codeine respectively while in treated wastewater, codeine levels were highest followed by BE and ephedrine. In general, the levels of the target compounds observed in this study are consistent with those reported in studies conducted in Europe (Bijlsma et al., 2012; Boleda et al., 2009; Pedrouzo et al., 2011; Van Nuijs et al., 2011) and the U.S.A. (Pal et al., 2013) as well as the only two other studies conducted in Canada (Metcalfe et al., 2010; Yargeau et al., in press).

All of the ATS included in this study were detected in untreated wastewater with the exception of MDA which was not detected using any sampling technique at any of the sampling locations at the WWTP. This is unlike another Canadian study which detected MDA in 32 of 40 samples of untreated wastewater (Metcalfe et al., 2010). The levels of ATS in untreated wastewater were slightly higher than those reported by Metcalfe et al. (2010) where levels of these compounds were less than $70 \mathrm{ng} \mathrm{L}^{-1}$. Methamphetamine levels were higher than those reported in Europe where they are generally $<10 \mathrm{ng} \mathrm{L}^{-1}$ but lower than those that have been reported in the U.S.A. (Chiaia et al., 2008).

Although the levels of cocaine and BE were in the range of those reported in other studies, the ratios of cocaine to BE in untreated wastewater were not. Ratios of cocaine to BE were in the range of 0.49 to 0.52 which are high compared to those reported in Europe and the U.S.A. where the ratio is typically much less than 0.50 (Castiglioni et al., 2006; Gheorghe et al., 2008; Mari et al., 2009; Metcalfe et al., 2010; Postigo et al., 2010; Zuccato et al., 2005). However, in a study conducted in Ireland, higher concentrations of cocaine relative to BE were also observed (Bones et al., 2007). Since it is expected that only $9 \%$ of a cocaine dose is excreted as the parent compound in urine, it is possible that the higher ratios observed here are due to direct disposal of cocaine in the sewage system (Kasprzyk-Hordern et al., 2009; Phillips et al., 2010).

In the case of opioids, dihydrocodeine and fentanyl were below their LOQs in all samples. This is to be expected for fentanyl since it has a tendency to be found in the sludge phase as opposed to the aqueous phase (log octanol water partitioning coefficient ( $\log \mathrm{K}_{\mathrm{ow}}$ ) of 4.05), 26 to $55 \%$ of the parent compound is excreted in urine as norfentanyl and only up to $6 \%$ is excreted as the parent compound (Baselt, 2004; Huerta-Fontela et al., 2008a; Thompson et al., 2011). Heroin was not detected in any samples which is consistent with other studies (Boleda et al., 2009; Yargeau et al., in press). It is known to be excreted mainly as morphine and acetylmorphine (Trescot et al., 2008) and may therefore contribute to it not being detected in this study. Finally, acetylmorphine was detected in $24 \mathrm{~h}$ composite and grab samples in spite of its tendency to be hydrolyzed to morphine.

\subsection{Comparison of DOA levels obtained by POCIS, $24 \mathrm{~h}$ composite and grab sampling}

As can be seen from Table 2, analytes were consistently detected using POCIS, $24 \mathrm{~h}$ composite and grab samples (100\% frequency in all cases). Those not detected in grab samples were also not detected in composite samples and POCIS, with the exception of those compounds for which $R_{s}$ are not available and for which comparison is not possible.

Analyte levels were generally comparable between POCIS and grab samples, and values for MDMA and methamphetamine are lower in POCIS as reported in a study conducted by Jones-Lepp et al. (2012). In addition, the levels of the target compounds in composite samples were generally comparable to those obtained using POCIS and grab sampling. The lower values obtained with POCIS may be explained by the fact that $R_{s}$ are determined at the lab scale in pure water and at ambient temperature which adds a potential source of error to the measurement of target compound levels when used in a heavy matrix such as wastewater.

One of the advantages of POCIS however, is the ability to detect target compounds that are often not detected using other sampling techniques since the analytes are accumulated over time in the POCIS sorbent. In this study however, MDA, dihydrocodeine and fentanyl were not quantifiable in POCIS as was the case in other samples. Therefore, the use of POCIS did not allow for additional compounds to be quantified in wastewater and in fact, since some $R_{S}$ were not available, fewer analytes could be quantified. In addition, it may not be possible to obtain sampling rates for certain compounds due to low uptake rates which may be attributed to the polarity of the compounds. This was the case for heroin, acetylcodeine and acetylmorphine for which sampling rates could not be determined (Yargeau et al., in press). It is important to note that although the data obtained via grab samples and POCIS were quite similar in this study, this is not always the case nor should it necessarily be (Jones-Lepp et al., 2012). In the case of POCIS, the integrated concentration of the analytes over the entire deployment period is obtained and often presents a better view of the concentration over time due to the potential of mixing or changes in human 
Table 2

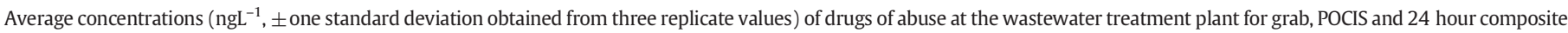
samples. MDA, fentanyl, dihydrocodeine and heroin are not included in the table since they were either not detected in any sample or were detected below their LOQs.

\begin{tabular}{|c|c|c|c|c|c|c|c|c|c|c|c|c|}
\hline & \multicolumn{4}{|l|}{ Grab } & \multicolumn{4}{|l|}{ POCIS } & \multicolumn{4}{|c|}{24 h composite } \\
\hline & $\begin{array}{l}\text { Untreated } \\
\text { WW }\end{array}$ & $\begin{array}{l}\text { Influent to } \\
\text { aeration }\end{array}$ & $\begin{array}{l}\text { Influent to } \\
\text { secondary } \\
\text { clarifier }\end{array}$ & $\begin{array}{l}\text { Treated } \\
\text { WW }\end{array}$ & $\begin{array}{l}\text { Untreated } \\
\text { WW }\end{array}$ & $\begin{array}{l}\text { Influent to } \\
\text { aeration }\end{array}$ & $\begin{array}{l}\text { Influent to } \\
\text { secondary } \\
\text { clarifier }\end{array}$ & $\begin{array}{l}\text { Treated } \\
\text { WW }\end{array}$ & $\begin{array}{l}\text { Untreated } \\
\text { WW }\end{array}$ & $\begin{array}{l}\text { Influent to } \\
\text { aeration }\end{array}$ & $\begin{array}{l}\text { Influent to } \\
\text { secondary } \\
\text { clarifier }\end{array}$ & $\begin{array}{l}\text { Treated } \\
\text { WW }\end{array}$ \\
\hline \multicolumn{13}{|c|}{ Cocaine and its metabolite } \\
\hline Cocaine & $869 \pm 20$ & $871 \pm 20$ & $83 \pm 5$ & $70 \pm 9$ & $1841 \pm 28$ & $1735 \pm 14$ & $367 \pm 4$ & $333 \pm 8$ & $903 \pm 6$ & $875 \pm 9$ & $83 \pm 5$ & $72 \pm 5$ \\
\hline Benzoylecgonine & $1594 \pm 58$ & $1616 \pm 66$ & $367 \pm 21$ & $356 \pm 15$ & $78 \pm 35$ & $76 \pm 28$ & $19 \pm 10$ & $18 \pm 25$ & $1855 \pm 24$ & $1750 \pm 18$ & $330 \pm 12$ & $298 \pm 11$ \\
\hline \multicolumn{13}{|c|}{ Amphetamine-type stimulants } \\
\hline Amphetamine & $68 \pm 8$ & $74 \pm 9$ & $17 \pm 2$ & $18 \pm 2$ & $78 \pm 7$ & $76 \pm 6$ & $19 \pm 3$ & $18 \pm 3$ & $85 \pm 5$ & $78 \pm 6$ & $13 \pm 3$ & $10 \pm 2$ \\
\hline Methamphetamine & $76 \pm 8$ & $79 \pm 2$ & $17 \pm 2$ & $16 \pm 2$ & $92 \pm 9$ & $83 \pm 3$ & $12 \pm 2$ & $9 \pm 1$ & $85 \pm 5$ & $80 \pm 3$ & $19 \pm 2$ & $14 \pm 2$ \\
\hline MDMA & $177 \pm 12$ & $192 \pm 10$ & $148 \pm 10$ & $140 \pm 2$ & $196 \pm 11$ & $192 \pm 10$ & $101 \pm 8$ & $96 \pm 5$ & $216 \pm 6$ & $210 \pm 4$ & $109 \pm 4$ & $99 \pm 6$ \\
\hline Ephedrine & $114 \pm 5$ & $136 \pm 10$ & $164 \pm 27$ & $141 \pm 15$ & $139 \pm 10$ & $136 \pm 10$ & $167 \pm 27$ & $165 \pm 24$ & $158 \pm 5$ & $140 \pm 5$ & $129 \pm 3$ & $118 \pm 4$ \\
\hline \multicolumn{13}{|l|}{ Opioid drugs } \\
\hline Codeine & $405 \pm 26$ & $464 \pm 15$ & $508 \pm 10$ & $477 \pm 33$ & $459 \pm 20$ & $460 \pm 24$ & $508 \pm 10$ & $497 \pm 9$ & $494 \pm 7$ & $456 \pm 3$ & $478 \pm 8$ & $519 \pm 4$ \\
\hline Acetylcodeine & $45 \pm 8$ & $46 \pm 11$ & $48 \pm 7$ & $55 \pm 3$ & $-^{a}$ & - & - & - & $70 \pm 6$ & $60 \pm 8$ & $43 \pm 3$ & $40 \pm 3$ \\
\hline Morphine & $42 \pm 5$ & $48 \pm 5$ & $45 \pm 3$ & $45 \pm 4$ & $56 \pm 6$ & $56 \pm 6$ & $43 \pm 4$ & $43 \pm 5$ & $76 \pm 4$ & $70 \pm 3$ & $54 \pm 3$ & $46 \pm 2$ \\
\hline Acetylmorphine & $137 \pm 12$ & $144 \pm 8$ & $98 \pm 7$ & $99 \pm 8$ & - & - & - & - & $142 \pm 4$ & $132 \pm 3$ & $91 \pm 3$ & $88 \pm 2$ \\
\hline Methadone & $42 \pm 5$ & $34 \pm 3$ & $54 \pm 4$ & $69 \pm 4$ & $40 \pm 5$ & $36 \pm 4$ & $55 \pm 5$ & $62 \pm 4$ & $63 \pm 4$ & $52 \pm 4$ & $59 \pm 3$ & $63 \pm 2$ \\
\hline Tramadol & $68 \pm 12$ & $58 \pm 6$ & $128 \pm 8$ & $125 \pm 10$ & $50 \pm 5$ & $41 \pm 4$ & $68 \pm 7$ & $73 \pm 4$ & $62 \pm 4$ & $48 \pm 5$ & $44 \pm 5$ & $67 \pm 3$ \\
\hline Ketamine & $67 \pm 9$ & $71 \pm 7$ & $22 \pm 7$ & $20 \pm 2$ & $84 \pm 7$ & $78 \pm 8$ & $22 \pm 3$ & $20 \pm 2$ & $90 \pm 5$ & $78 \pm 3$ & $21 \pm 5$ & $18 \pm 2$ \\
\hline Oxycodone & $65 \pm 6$ & $55 \pm 5$ & $52 \pm 4$ & $52 \pm 4$ & $69 \pm 6$ & $62 \pm 2$ & $52 \pm 4$ & $52 \pm 3$ & $78 \pm 4$ & $79 \pm 3$ & $65 \pm 5$ & $58 \pm 2$ \\
\hline EDDP & $93 \pm 6$ & $103 \pm 9$ & $131 \pm 12$ & $144 \pm 5$ & $107 \pm 5$ & $103 \pm 9$ & $125 \pm 5$ & $130 \pm 5$ & $107 \pm 4$ & $103 \pm 2$ & $94 \pm 3$ & $87 \pm 5$ \\
\hline
\end{tabular}

a Dashes represent values that were not obtained for compounds whose sampling rates are not available.

activities (e.g. drug consumption patterns that change as a function of the day of the week) (Gerrity et al., 2011; Managaki et al., 2008; Ort et al., 2005).

\subsection{Removal of DOAs by wastewater treatment}

Table 3 presents the removal efficiencies estimated by load data using different approaches. The removal efficiencies for the $24 \mathrm{~h}$ composites were calculated by mass balancing daily loads of influent and effluent, and then by using the captured fractions of the sampled influent by effluent sampling accounting for time-shift and hydraulic mixing. Most of the removal of the target compounds was observed during biological treatment which is generally the case for organic contaminants in wastewater (Blair et al., 2013; Joss et al., 2006; Khan and Ongerth, 2002). In some cases however, comparable levels of removal were also noted during primary and secondary clarification.

Table 3

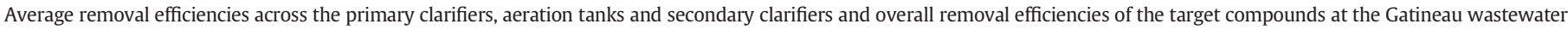
treatment plant, QC, Canada.

\begin{tabular}{|c|c|c|c|c|c|c|c|c|c|c|c|c|c|c|c|c|}
\hline \multirow[t]{3}{*}{ Compound } & \multicolumn{16}{|c|}{ Removal efficiencies (\%) } \\
\hline & \multicolumn{4}{|c|}{ Primary clarifiers } & \multicolumn{4}{|c|}{ Aeration tanks } & \multicolumn{4}{|c|}{ Secondary clarifiers } & \multicolumn{4}{|c|}{ Overall } \\
\hline & Grab & POCIS & $\begin{array}{l}24 \mathrm{~h} \\
\text { comp. }\end{array}$ & $\begin{array}{l}\text { Time-shifted } \\
\text { mass balance }\end{array}$ & Grab & POCIS & $\begin{array}{l}24 \mathrm{~h} \\
\text { comp. }\end{array}$ & $\begin{array}{l}\text { Time-shifted } \\
\text { mass balance }\end{array}$ & Grab & POCIS & $\begin{array}{l}24 \mathrm{~h} \\
\text { comp. }\end{array}$ & $\begin{array}{l}\text { Time-shifted } \\
\text { mass balance }\end{array}$ & Grab & POCIS & $\begin{array}{l}24 \mathrm{~h} \\
\text { comp. }\end{array}$ & $\begin{array}{l}\text { Time-shifted } \\
\text { mass balance. }\end{array}$ \\
\hline \multicolumn{17}{|c|}{ Cocaine and its metabolite } \\
\hline Cocaine & 0 & 0 & 0 & N.A. & 90 & 91 & 91 & 73 & 15 & 13 & 14 & 17 & 92 & 92 & 92 & 90 \\
\hline Benzoylecgonine & -1 & 6 & 2 & N.A. & 77 & 79 & 81 & 66 & 3 & 9 & 10 & 17 & 78 & 82 & 84 & 85 \\
\hline \multicolumn{17}{|c|}{ Amphetamine-type stimulants } \\
\hline Amphetamine & -8 & 2 & 5 & N.A. & 76 & 75 & 84 & 66 & -2 & 7 & 18 & 23 & 74 & 77 & 88 & 90 \\
\hline Methamphetamine & -4 & 10 & 3 & N.A. & 78 & 86 & 77 & 60 & 6 & 26 & 25 & 19 & 78 & 91 & 83 & 82 \\
\hline $\mathrm{MDA}^{\mathrm{b}}$ & - & - & - & N.A. & - & - & - & - & - & - & - & - & - & - & - & - \\
\hline MDMA & -8 & 2 & -1 & N.A. & 23 & 48 & 49 & 45 & 6 & 5 & 8 & 8 & 21 & 51 & 53 & 54 \\
\hline Ephedrine & -19 & 2 & 9 & N.A. & -20 & -22 & 9 & 7 & 14 & 1 & 8 & 18 & -24 & -19 & 24 & 34 \\
\hline \multicolumn{17}{|l|}{ Opioid drugs } \\
\hline Codeine & -15 & 0 & 4 & N.A. & -10 & -11 & -3 & 3 & 6 & 2 & -9 & 4 & -18 & -8 & -7 & 13 \\
\hline Acetylcodeine $^{c}$ & -3 & - & 11 & N.A. & -4 & - & 28 & 35 & -15 & - & 6 & 8 & -23 & - & 41 & 53 \\
\hline Dihydrocodeine ${ }^{\mathrm{b}}$ & - & - & - & N.A. & - & - & - & - & - & - & - & - & - & - & - & - \\
\hline Morphine & -15 & -1 & 5 & N.A. & 7 & 24 & 24 & 25 & 0 & 0 & 14 & 8 & -7 & 23 & 38 & 39 \\
\hline Acetylmorphine $^{c}$ & -5 & - & 4 & N.A. & 32 & - & 32 & 27 & -1 & - & 3 & 9 & 28 & - & 37 & 40 \\
\hline Methadone & 10 & 10 & 14 & N.A. & -53 & -53 & -11 & 10 & -13 & -13 & -8 & 4 & -56 & -56 & -3 & 25 \\
\hline Heroin ${ }^{b, c}$ & - & - & - & N.A. & - & - & - & - & - & - & - & - & - & - & - & - \\
\hline Tramadol & 14 & 17 & 21 & N.A. & -121 & -64 & 7 & 11 & 3 & -7 & -51 & 3 & -84 & -46 & -10 & 37 \\
\hline Ketamine & -6 & 6 & 9 & N.A. & 69 & 71 & 73 & 64 & 8 & 10 & 13 & 17 & 70 & 76 & 80 & 84 \\
\hline Oxycodone & 15 & 11 & -4 & N.A. & 5 & 15 & 19 & 10 & 1 & 0 & 9 & 21 & 21 & 24 & 24 & 28 \\
\hline EDDP & -10 & 4 & 0 & N.A. & -28 & -21 & 11 & 11 & -10 & -4 & 8 & 12 & -55 & -22 & 18 & 26 \\
\hline Fentanyl $^{\mathrm{b}}$ & - & - & - & N.A. & - & - & - & - & - & - & - & - & - & - & - & - \\
\hline
\end{tabular}

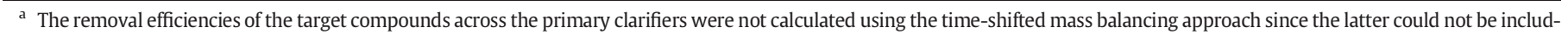
ed in the model.

b Below the LOD or LOQ.

c POCIS sampling rate not available. 
During primary clarification, the highest removals observed were those for tramadol (21\% using composite sample data) while all other compounds exhibited removals $\leq 15 \%$. In addition, 11 of the 15 quantified analytes in grab samples exhibited negative removals while only one negative removal was observed using POCIS and traditional $24 \mathrm{~h}$ composite data. The removals of the target analytes were not calculated using the time-shifted mass balancing approach since primary clarifiers could not be included in the model used to calculate the load fractions captured by the autosamplers.

Removals during biological treatment were generally lower using the time-shifted mass balancing approach as compared to other mass balances. Considering the time-shifted removal data, the highest removal was observed for cocaine where $73 \%$ of the compound that entered aeration tanks was removed. The lowest removal was observed for codeine of which only $3 \%$ was removed, followed by ephedrine (7\%), methadone (10\%), oxycodone (10\%), tramadol (11\%), and EDDP (11\%). Although, the majority of organic contaminant removal takes place during biological treatment, the persistence of some of these compounds during wastewater treatment is primarily due to their resistance to biodegradation (Joss et al., 2006; Khan and Ongerth, 2002). All of the analytes that exhibited negative removals during this treatment step using grab (6 analytes), POCIS ( 5 analytes) and 24 h composite sample ( 2 analytes) data turned into positive removals using the time-shifted approach.

During secondary clarification the most significant removal was observed for methamphetamine according to POCIS, traditional and time-shifted composite data. All other compounds exhibited removals of $\leq 21 \%$ including 3 negative removals for POCIS and 5 for grab samples. Removals calculated using the traditional $24 \mathrm{~h}$ composite approach reveal 3 negative values whereas those calculated using the same data but with fractionation generated no negative removal values.

Overall removals of cocaine, benzoylecgonine and amphetaminetype stimulants were generally in the range of those reported by others even though the latter are known to be very sensitive to different treatment technologies and often exhibit negative removals during treatment (Bijlsma et al., 2012; Boleda et al., 2007; Bones et al., 2007; Loganathan et al., 2009; Metcalfe et al., 2010; Postigo et al., 2008a,b, 2010; Valcárcel et al., 2012; Yargeau et al., in press). The discrepancies with the removals reported in literature and those observed in this study may be due to various factors such as the type of treatment process used at the treatment plant under investigation (Joss et al., 2006; Kanda et al., 2003), the solids and hydraulic retention times (Clara et al., 2005; Kreuzinger et al., 2004; Tauxe-Wuersch et al., 2005), the dilution of influent wastewater by rain events during the sampling period (Joss et al., 2006; Tauxe-Wuersch et al., 2005; Ternes, 1998) and very likely by the calculation used to obtain the removals themselves.

In the case of opioids, removals of ketamine and acetylmorphine were in the range of those reported in other studies (Bijlsma et al., 2012; Huerta-Fontela et al., 2008b). Overall codeine removal was negative except in the case of the time-shifted removal where it was only $13 \%$. It remains unclear, if this is due to the cleavage of codeine-6glucuronide to free codeine during the treatment process (Boleda et al., 2009) or a bias of the sampling scheme. Negative removals of this compound were also observed using POCIS and traditional $24 \mathrm{~h}$ composite sampling in a study conducted by Yargeau et al. (in press). The average overall removal of morphine was 39\% using the timeshifted approach which is lower than that reported by Boleda et al. (2009) where $73 \%$ overall removal was observed. However, the cleavage of morphine glucuronide conjugates to form morphine can account for low or negative removals of the drug during wastewater treatment (Baselt, 2004). POCIS and grab data reveal that EDDP exhibit -22 and $-55 \%$ overall removals which are consistent with another study (Yargeau et al., in press). Other studies have observed negligible or no removal of EDDP (Boleda et al., 2009; Castiglioni et al., 2006) whereas time-shifted and traditional composite sample removals were 26 and $18 \%$, respectively for this study.
Negative removals using grab sampling data are not uncommon since this sampling technique does not capture short or long-term concentration variation and as expected some grab sample removals were negative. For the removals using traditional $24 \mathrm{~h}$ composite sampling, even though a sampling frequency of 32 times per day (equivalent to every 45 min over a 24 h period) was used, it was not sufficient to avoid negative removals. This may be due to the fact that time proportional as opposed to flow proportional sampling was used which has been known to over- or underestimate the target compound concentration (Ort et al., 2010b). In addition, the negative removals may be true negative values due to the release of these compounds from fecal particles (since many of the selected compounds are excreted to varying extents in feces) or the transformation of conjugate compounds to the parent compound during the biological treatment step (Göbel et al., 2007; Monteiro and Boxall, 2010; Salgado et al., 2012; Ternes, 1998). However, the removals obtained using the time-shifted approach demonstrate that negative overall removal values and removals for each treatment unit were no longer obtained. This suggests that the most significant reason for the observed negative removals obtained when using grab or $24 \mathrm{~h}$ composite sampling is that the two largely different loads (water volumes) are used to calculate the removals.

It is important to note however, that negative POCIS removals cannot be explained by mixing regime characteristics since POCIS levels represent time-weighted average concentrations of the target compounds. Moreover, the long exposure time of 14 days is supposed to average out day-to-day concentration variability. However, as mentioned in Section 3.3, the $R_{s}$ are determined in the lab and are then used to calculate analyte levels in both the influent and effluent, which are quite different matrices, and where in reality the $R_{s}$ are surely different due to the heavy matrix of the influent. In the influent there is likely to be increased inhibition due to clogging, fouling, biofilm accumulation, etc. and improved calibration strategies, such as the in-situ calibration proposed by Harman et al. (2011) would certainly improve the reliability of the removal levels determined using POCIS data.

\section{Conclusions}

The levels of the target compounds obtained were consistent with estimates reported in other studies and further confirm the ubiquitous presence of DOAs in wastewater of urban areas. The results also contribute to expanding the data available for these compounds in wastewater which to date are scarce and add to the database required for environmental fate and risk assessment. In addition, the low removal of the targeted DOAs indicates that the potential exists for adverse effects on the aquatic organisms in surface waters.

The removal efficiency results obtained in this study demonstrate for the first time the application of a time-shifted mass balancing approach to reliably match influent loads to effluent loads in the calculation of DOA removals during wastewater treatment. The results indicate that negative removals obtained using other sampling and calculation methods can be successfully corrected when the timeshifted approach is applied. It further demonstrates the importance of using adequate sampling and calculation approaches for proper evaluation of removal efficiencies of target compounds during water treatment.

\section{Acknowledgments}

We gratefully acknowledge the assistance of Deniz Nasuhoglu, Yves Dionne and the staff at the wastewater treatment plant for aid in collecting the samples. This work was supported by the Natural Sciences and Engineering Council (NSERC) of Canada through a Discovery grant and a Strategic Project grant to Dr. Yargeau. We thank NSERC for a post graduate doctoral scholarship awarded to Angela Rodayan. We also thank the Fonds québécois de la recherche sur la nature et les 
technologies for a doctoral scholarship awarded to Angela Rodayan. Finally, we would like to thank the Karlsruhe House of Young Scientists (KHYS) of the Karlsruhe Institute of Technology (KIT) for supporting the work of Dr. Majewsky.

\section{References}

Alvarez DA, Petty JD, Huckins JN, Jones-Lepp TL, Getting DT, Goddard JP, et al. Development of a passive, in situ, integrative sampler for hydrophilic organic contaminants in aquatic environments. Environ Toxicol Chem 2004;23:1640-8.

Anhert M, Kuhn V, Krebs P. Temperature as an alternative tracer for the determination of mixing characteristics in wastewater treatment plants. Water Res 2010;44: 1765-76.

Bailly E, Levi Y, Karolak S. Calibration and field evaluation of polar organic chemical integrative sampler (POCIS) for monitoring pharmaceuticals in hospital wastewater. Environ Pollut 2013;174:100-5.

Baselt RC. Disposition of toxic drugs and chemicals in man. Foster City, CA: Biomedical Publications; 2004

Bijlsma L, Emke E, Hernández F, de Voogt P. Investigation of drugs of abuse and relevant metabolites in Dutch sewage water by liquid chromatography coupled to high resolution mass spectrometry. Chemosphere 2012;89:1399-406.

Blair BD, Crago JP, Hedman CJ, Treguer RJF, Magruder C, Royer LS, et al. Evaluation of a model for the removal of pharmaceuticals, personal care products, and hormones from wastewater. Sci Total Environ 2013;444:515-21.

Boleda MR, Galceran MT, Ventura F. Trace determination of cannabinoids and opiates in wastewater and surface waters by ultra-performance liquid chromatography-tandem mass spectrometry. J Chromatogr A 2007;1175:38-48.

Boleda MR, Galceran MT, Ventura F. Monitoring of opiates, cannabinoids and their metabolites in wastewater, surface water and finished water in Catalonia, Spain. Water Res 2009;43:1126-36.

Bones J, Thomas KV, Paull B. Using environmental analytical data to estimate levels of community consumption of illicit drugs and abused pharmaceuticals. J Environ Monit 2007;9.

Castiglioni S, Zuccato E, Crisci E, Chiabrando C, Fanelli R, Bagnati R. Identification and measurement of illicit drugs and their metabolites in urban wastewater by liquid chromatography-tandem mass spectrometry. Anal Chem 2006;78:8421-9.

Chiaia AC, Banta-Green C, Field J. Eliminating solid phase extraction with large-volume injection LC/MS/MS: analysis of illicit and legal drugs and human urine indicators in US wastewaters. Environ Sci Technol 2008;42:8841-8.

Clara M, Kreuzinger N, Strenn B, Gans O, Kroiss H. The solids retention time-a suitable design parameter to evaluate the capacity of wastewater treatment plants to remove micropollutants. Water Res 2005;39:97-106

Gerrity D, Trenholm RA, Snyder SA. Temporal variability of pharmaceuticals and illicit drugs in wastewater and the effects of a major sporting event. Water Res 2011;45: 5399-411.

Gheorghe A, van Nuijs A, Pecceu B, Bervoets L, Jorens PG, Blust R, et al. Analysis of cocaine and its principal metabolites in waste and surface water using solid-phase extraction and liquid chromatography-ion trap tandem mass spectrometry. Anal Bioanal Chem 2008;391:1309-19.

Göbel A, McArdell CS, Joss A, Siegrist H, Giger W. Fate of sulfonamides, macrolides, and trimethoprim in different wastewater treatment technologies. Sci Total Environ 2007;372:361-71.

Greenwood R, Mills GA, Vrana B. Passive sampling techniques in environmental monitoring. In: Barcelo D, editor. Comprehensive analytical chemistry, 48. Amsterdam, The Netherlands: Elsevier; 2007.

Harman C, Reid M, Thomas KV. In situ calibration of a passive sampling device for selected illicit drugs and their metabolites in wastewater, and subsequent year-long assessment of community drug usage. Environ Sci Technol 2011;45:5676-82.

Huerta-Fontela M, Galceran MT, Ventura F. Ultraperformance liquid-chromatographytandem mass spectrometry analysis of stimulatory drugs of abuse in wastewater and surface waters. Anal Chem 2007;79:3821-9.

Huerta-Fontela M, Galceran MT, Martin-Alonso J, Ventura F. Occurrence of psychoactive stimulatory drugs in wastewaters in north-eastern Spain. Sci Total Environ 2008a; 397:31-40.

Huerta-Fontela M, Galceran MT, Ventura F. Stimulatory drugs of abuse in surface waters and their removal in a conventional drinking water treatment plant. Environ Sci Technol 2008b;42:6809-16.

Hummel D, Loeffler D, Fink G, Ternes TA. Simultaneous determination of psychoactive drugs and their metabolites in aqueous matrices by liquid chromatography mass spectrometry. Environ Sci Technol 2006;40.

Irvine RJ, Kostakis C, Felgate PD, Jaehne EJ, Chen C, White JM. Population drug use in Australia: a wastewater analysis. Forensic Sci Int 2011;210:69-73.

Jones-Lepp TL, Sanchez C, Alvarez DA, Wilson DC, Taniguchi-Fu R-L. Point sources of emerging contaminants along the Colorado River Basin: source water for the arid Southwestern United States. Sci Total Environ 2012:430:237-45.

Joss A, Zabczynski S, Göbel A, Hoffmann B, Löffler D, McArdell CS, et al. Biological degradation of pharmaceuticals in municipal wastewater treatment: proposing a classification scheme. Water Res 2006;40:1686-96.

Kanda R, Griffin P, James HA, Fothergill J. Pharmaceutical and personal care products in sewage treatment works. J Environ Monit 2003;5:823-30.

Kasprzyk-Hordern B, Dinsdale RM, Guwy AJ. Illicit drugs and pharmaceuticals in the environment - forensic applications of environmental data. Part 1: estimation of the usage of drugs in local communities. Environ Pollut 2009;157:1773-7.
Khan SJ, Ongerth JE. Estimation of pharmaceutical residues in primary and secondary sewage sludge based on quantities of use and fugacity modelling. Water Sci Techno 2002;46:105-13.

Kreuzinger N, Clara M, Strenn B, Vogel B. Investigation on the behaviour of selected pharmaceuticals in the groundwater after infiltration of treated wastewater. Water Sci Technol 2004;50:221-8.

Li H, Helm PA, Metcalfe C. Sampling in the Great Lakes for pharmaceuticals, personal care products and endocrine disrupting substances using the passive polar organic chemical integrative sampler. Environ Toxicol Chem 2010;29:751-62.

Loganathan B, Phillips M, Mowery H, Jones-Lepp TL. Contamination profiles and mass loadings of macrolide antibiotics and illicit drugs from a small urban wastewate treatment plant. Chemosphere 2009;75:70-7.

Majewsky M, Gallé T, Bayerle M, Goel R, Fischer K, Vanrolleghem PA. Xenobiotic removal efficiencies in wastewater treatment plants: residence time distributions as a guiding principle for sampling strategies. Water Res 2011;45:6152-62.

Majewsky M, Farlin J, Bayerle M, Galle T. A case-study on the accuracy of mass balances for xenobiotics in full-scale wastewater treatment plants. Environ Sci Process Impact 2013:15:730-8.

Managaki S, Kim W, Furumai H, Takada H. The difference of diurnal behavior of pharmaceuticals and gross organic pollutants in combined sewer system. 11th international conference on urban drainage, Edinburgh, Scotland, UK; 2008. p. 7.

Mari F, Politi L, Biggeri A, Accetta G, Trignano C, Di Padua M, et al. Cocaine and heroin in waste water plants: a 1-year study in the city of Florence, Italy. Forensic Sci Int 2009; 189:88-92.

Mazzella N, CDubernet JF, Delmas F. Determination of kinetic and equilibrium regimes in the operation of polar organic chemicals integrative samplers - application to the passive sampling of the polar herbicides in aquatic environments. J Chromatogr A 2007; 1154:42-51

Metcalfe C, Tindale K, Li H, Rodayan A, Yargeau V. Illicit drugs in Canadian municipa wastewater and estimates of community drug use. Environ Pollut 2010;158 3179-85.

Mills G, Vrana B, Allan I, Alvarez D, Huckins J, Greenwood R. Trends in monitoring pharmaceuticals and personal-care products in the aquatic environment by use of passive sampling devices. Anal Bioanal Chem 2007;387:1153-7.

Monteiro SC, Boxall ABA. Occurrence and fate of human pharmaceuticals in the environment. In: Whitcare DM, editor. Rev Environ Contam Toxicol, 202. ; 2010. p. 53-154

Nefau T, Karolak S, Castillo L, Boireau V, Levi Y. Presence of illicit drugs and metabolites in influents and effluents of 25 sewage water treatment plants and map of drug consumption in France. Sci Total Environ 2013;461-462:712-22.

Olivet D, Valls J, Gordillo MÀ, Freixó À, Sánchez A. Application of residence time distribution technique to the study of the hydrodynamic behaviour of a full-scale wastewate treatment plant plug-flow bioreactor. J Chem Technol Biotechnol 2005;80:425-32.

Ort C, Schaffner C, Giger W, Gujer W. Modeling stochastic load variations in sewer systems. Water Sci Technol 2005;52:113-22.

Ort C, Lawrence MG, Reungoat J, Mueller JF. Sampling for PPCPs in wastewater systems: comparison of different sampling modes and optimization strategies. Environ Sci Technol 2010a;44:6289-96.

Ort C, Lawrence MG, Rieckermann J, Joss A. Sampling for pharmaceuticals and personal care products (PPCPs) and illicit drugs in wastewater systems: are conclusions valid? A critical review. Environ Sci Technol 2010b;44:6024-35.

Pal R, Megharaj M, Kirkbride KP, Naidu R. Illicit drugs and the environment - a review. Sci Total Environ 2013;463-464:1079-92.

Pedrouzo M, Borrull F, Pocurull E, Marce R. Drugs of abuse and their metabolites in waste and surface waters by liquid chromatography tandem mass spectrometry. J Sep Sci 2011;34:1091-101.

Petty JD, Huckins JN, Alvarez DA, Brumbaugh WG Cranor WL Gale RW, et al A holistic passive integrative sampling approach for assessing the presence and potential impacts of water borne environmental contaminants. Chemosphere 2004;54:695-705.

Phillips PJ, Smith SG, Kolpin DW, Zaugg SD, Buxton H, Furlong E, et al. Pharmaceutical formulation facilities as sources of opioids and other pharmaceuticals to wastewate treatment effluents. Environ Sci Technol 2010;44(13):4910-6.

Postigo C, Lopez de Alda MJ, Barcelo D. Analysis of drugs of abuse and their human metabolites in water by LC-MS': a non-intrusive tool for drug abuse estimation at the community level. Trends Anal Chem 2008a;27:1053-69.

Postigo C, de Alda MJ Lopez, Barcelo D. Fully automated determination in the low nanogram per liter level of different classes of drugs of abuse in sewage water by on-line solid-phase extraction-liquid chromatography-electrospray-tandem mass spectrometry. Anal Chem 2008b;80:3123-34.

Postigo C, Lopez de Alda MJ, Barcelo D. Drugs of abuse and their metabolites in the Ebro River Basin: occurrence in sewage and surface water, sewage treatment plants removal efficiency, and collective drug usage estimation. Environ Pollut 2010;36:75-84.

Postigo C, Lopez de Alda MJ, Barcelo D. Occurrence of illicit drugs in wastewater in Spain. In: Castiglioni S, Zuccato E, Fanelli R, editors. Illicit drugs in the environment: occurrence, analysis, and fate using mass spectrometry. Hoboken, New Jersey: John Wiley \& Sons, Inc.; 2011. p. 117-36.

Ramsey MH, Thompson M. Uncertainty from sampling, in the context of fitness for purpose. Accredit Qual Assur 2007:12:503-13.

Rodayan A, Segura PA, Yargeau V. Ozonation of wastewater: removal and transformation products of drugs of abuse. Sci Total Environ 2014. http://dx.doi.org/10.1016/j. scitotenv.2013.11.023.

Salgado R, Marques R, Noronha JP, Carvalho G, Oehmen A, Reis MAM. Assessing the removal of pharmaceuticals and personal care products in a full-scale activated sludge plant. Environ Sci Pollut Res 2012;19:1818-27.

Tauxe-Wuersch A, De Alencastro LF, Grandjean D, Tarradellas J. Occurrence of severa acidic drugs in sewage treatment plants in Switzerland and risk assessment. Water Res 2005;39:1761-72. 
Ternes TA. Occurrence of drugs in German sewage treatment plants and rivers. Water Res 1998;32:3245-60.

Thompson K, Zhang J, Zhang C. Use of fugacity model to analyze temperature-dependent removal of micro-contaminants in sewage treatment plants. Chemosphere 2011;84: 1066-71.

Trescot AM, Datta S, Lee M, Hansen H. Opioid pharmacology. Pain Physician 2008: S133-53. [Opioid Special Issue 2008].

UNODCWorld drug report 2008. Vienna, Austria: United Nations Office on Drugs and Crime; 2008.

Valcárcel Y, Martínez F, González-Alonso S, Segura Y, Catalá M, Molina R, et al. Drugs of abuse in surface and tap waters of the Tagus River basin: heterogeneous photo-Fenton process is effective in their degradation. Environ Int 2012;41: 35-43.
Van Nuijs A, Castiglioni S, Tarcomnicu I, Postigo C, Lopez de Alda MJ, Neels H, et al. Illicit drug consumption estimations derived from wastewater analysis: a critical review. Sci Total Environ 2011;409:3564-77.

Yargeau V, Taylor B, Li H, Rodayan A, Metcalfe CD. Analysis of drugs of abuse in wastewater from two Canadian cities. Sci Total Environ 2014. http://dx.doi.org/10.1016/j. scitotenv.2013.11.094

Zhang Z, Hibberd A, Zhou JL. Analysis of emerging contaminants in sewage effluent and river water: comparison between spot and passive sampling Anal Chim Acta 2008:607:37-44.

Zuccato E, Castiglioni S. Illicit drugs in the environment. Philos Trans R Soc Lond A 2009; 367:3965-78.

Zuccato E, Chiabrando C, Castiglioni S, Calamari D, Bagnati R, Schiarea S, et al. Cocaine in surface waters: a new evidence-based tool to monitor community drug abuse. Environ Health 2005;4. 